\title{
Relationships between Subjective and Objective Acoustical Measures in Churches
}

\author{
Antonio. P.O. Carvalho ${ }^{1}$, Antonio E.J. Morgado ${ }^{1}$ and Luis Henrique ${ }^{2}$ \\ ${ }^{1}$ Acoustical Laboratory, Dep of Civil Engineering, College of Engineering, $U$ of Porto, R Bragas, \\ P-4099 Porto Codex, Portugal; ${ }^{2}$ School of Music and Performing Arts, \\ Polytechnic Institute of Porto, R Alegria, 503, P-4000 Porto, Portugal
}

\begin{abstract}
This study reports on subjective and objective acoustical field measurements made in a survey of 36 Catholic churches in Portugal built in the last 14 centuries. Monaural acoustical measurements (RT, EDT. C80, D50. TS and L) were taken at several source/receiver locations in each church and a group of college students was asked to judge the subjective quality of music. The listeners in each church evaluated live music performances at similar locations in each room. Evaluation sheets were used to record the listeners' overall impressions of room acoustic quality and also Loudness, Reverberance. Intimacy, Envelopment, Directionality, Balance, Clarity Echoes and Background Noise. This paper concentrates on the relationships of the subjective pararneters with the objective room acoustics measures and with the architectural features of the churches. Correlation analyses and statistical modeling identified significant relationships among the measures. For instance, linear correlation coefficients ( $|\mathrm{R}|$ ) of 0.8-0.9 were found for the relationships: Reverberance/RT and Clarity/C80; the maximum | R I found was 0.93 for Echoes/RT. Regarding architectural features the maximum I R I found was 0.87 between Intimacy and Total Volume.
\end{abstract}

\section{INTRODUCTION}

This study is part of a research program initiated in 1991 by Carvalho at the University of Porto and University of Florida ${ }^{1}$. The aim of the project is to explore methods to evaluate, predict and preview the acoustical qualities of churches. The program has included two major components to date:

- Objective studies of existing churches - Measurements were taken in 41 Portuguese Catholic churches, at multiple locations in each room. Several objective acoustical parameters were measured (RT, EDT, C80, D50, TS, L, BR_RT, BR_L, RASTI) ${ }^{1}$.

- $\quad$ Subjective studies of existing churches - This has included both evaluating live musical performances in 36 churches and speech intelligibility testing. This work is characterized by the use of a sample of listeners, evaluation of several locations in each room, assessment of many rooms and comprehensive statistical analysis of the data ${ }^{2}$. 
This paper presents a report concerning relationships between subjective and objective acoustical parameters and with the architectural features found in this large sample of churches.

\section{METHODOLOGY}

\subsection{Method Summary}

The main research hypothesis is that the perceptions of people who attend services or concerts in churches could be measured and then related with objective room acoustics measures and architectural features. The among-room variations of subjective scores can be viewed as differences that result from the architectural and objective acoustical proprieties of the churches that experience shows actually exist. Therefore strategies to measure and predict these variations would be helpful to acoustical consultants and architects.

The study consisted of two parts, both involving analyses in (almost) empty churches. The first part was to gather objective results of the main room acoustics measures. The second part was to gather subjective evaluations from listeners, using live music performances, of the acoustical qualities of the churches using the same sample of churches.

There are certain limitations using this type of methodology for evaluation. The acoustical response of the church changes when it is fully occupied and the character of the music heard during a religious service or during a musical performance is likely different. Nevertheless this methodology gives a normalized acoustic environment that could be easily used for comparison.

\subsection{Sample of Churches Used}

The investigation is focused on the Roman Catholic churches of Portugal. Portugal is one of the oldest European countries and played a prominent role in some of the most significant events in world history. It presents an almost perfect location to trace the history of Catholic church buildings and Portuguese churches can be considered representative of Catholic churches in the world.

This study reports on acoustical field measurements conducted between June 1993 and January 1996 in a major survey of 36 Roman Catholic churches in Portugal that were built between the 6th century and the 1960's. Table I presents an alphabetical list of the churches tested in the survey. The churches are a sample of 14 centuries of church building. The oldest church tested was number 14 (Lourosa), which was built around the 6-7th century. The most recent was church number 18 (N.S. Boavista-Porto), which was completed in the 1960's.

The churches were selected to represent the main architectural styles found throughout Portugal and to represent the evolution of church construction in Portugal. The summary of the architectural styles of the churches are presented in Table 2. For more uniformity of the sample, only churches with a room volume of less than 19000 $\mathrm{m}^{3}$ were selected for the study.

The churches were also grouped chronologically: 12 Visigothic or Romanesque churches (6th-13th centuries), 11 Gothic or Manueline churches (13th-16th centuries), 9 Renaissance or Baroque churches (16th-18th centuries) and 4 Neoclassic or Contemporary churches (18th-20th century). The main architectural features of these churches are displayed in Table 3.

A complete objective acoustical analysis of these churches is available ${ }^{1}$ and also the overall results regarding the subjective acoustic parameters ${ }^{2}$. 
Table 1. List of the 36 churches tested

\begin{tabular}{rlrllr}
\hline N. & Church Name & Vol $\left.\mathbf{( m}^{\mathbf{3}}\right)$ & N. & Church Name & Vol $\left(\mathbf{m}^{\mathbf{3}}\right)$ \\
\hline 1 & Almansil & 578 & 19 & Paco de Sousa & 6028 \\
2 & Armamar & 2487 & 20 & Sant Sacram (Porto) & 6816 \\
3 & Bas Estrela (Lisboa) & 18674 & 21 & S B Castris (Evora) & 1314 \\
4 & Bravaes & 946 & 22 & S Francisco (Evora) & 18631 \\
5 & Bustelo & 6476 & 23 & S Gens (Boelhe) & 299 \\
6 & Cabeca Santa & 751 & 24 & S Pedrode Ferreira & 2912 \\
7 & Caminha & 5899 & 25 & S Pedro de Rates & 3918 \\
8 & Cedofeita-old (Porto) & 1117 & 26 & S Pedro de Roriz & 2198 \\
9 & Cete & 1515 & 27 & S Roque (Lisboa) & 14207 \\
10 & Clerigos (Porto) & 5130 & 28 & Se (Lamego) & 13424 \\
11 & Golega & 5563 & 29 & Se (Porto) & 15260 \\
12 & Lapa (Porto) & 11423 & 30 & Se (Silves) & 10057 \\
13 & Lecado Bailio & 9795 & 31 & Serrado Pilar (Gaia) & 11566 \\
14 & Lourosa & 1163 & 32 & Tibaes & 8608 \\
15 & Mertola & 1950 & 33 & VianadoAlentejo & 3358 \\
16 & Misericordia (Évora) & 3338 & 34 & Vila do Bispo & 1290 \\
17 & Moura & 6300 & 35 & V N Azeitao & 1239 \\
18 & N S Boavista (Porto) & 3740 & 36 & Vouzela & 1148
\end{tabular}

Table 2. Architectural styles of the 36 churches tested

$\begin{array}{lll}1 & \text { Visigothic } & \text { (6th-11th centuries) } \\ 2 & \text { Romanesque } & \text { (12th-13th centuries) } \\ 3 & \text { Gothic } & \text { (13th-15th centuries) } \\ 4 & \text { Manueline } & \text { (15th-16th centuries) } \\ 5 & \text { Renaissance } & \text { (16th-17th centuries) } \\ 6 & \text { Baroque } & \text { (17th-18th centuries) } \\ 7 & \text { Neoclassic } & \text { (18th-19th centuries) } \\ 8 & \text { Contemporary } & \text { (20th century) }\end{array}$

Table 3. Simple statistics for architectural features of all 36 churches tested

\begin{tabular}{llrrrr}
\hline Architectural Feature & & Minimum & Median & Mean & Maximum \\
\hline Volume & $\left(\mathrm{m}^{3}\right)$ & 299 & 3829 & 5809 & 18674 \\
Area & $\left(\mathrm{m}^{2}\right)$ & 56 & 424 & 448 & 1031 \\
Maximum height & $(\mathrm{m})$ & 6 & 14 & 15 & 39 \\
Maximumlength & $(\mathrm{m})$ & 13 & 31 & 34 & 62 \\
Width nave & $(\mathrm{m})$ & 5 & 11 & 12 & 26
\end{tabular}




\subsection{Measurement Method for Objective Measures}

Six objective room acoustics parameters were calculated in each church using the Impulse Response Method (a sound source generates sound within the room and a receiving section acquires the sound pressure signal after the sound source ceases emit). They are:

- $R T$ Reverberation Time using the integrated impulse-response method. RT30 (from -5 to $-35 \mathrm{~dB}$ );

- EDT Early Decay Time. EDT10 (from 0 to $-10 \mathrm{~dB}$ );

- C80 Early to Late Sound Index or Clarity with a time window of $80 \mathrm{~ms}$. $C 80=10 \log \mathrm{E}(0,80) / \mathrm{E}(80, \infty) ;$

- D Early to Total Energy Ratio (Early Energy Fraction, Definition or Deutlichkeit) with a time window of $50 \mathrm{~ms}$.

$$
\mathrm{D}=\mathrm{E}(0,50) / \mathrm{E}(0, \infty)
$$

- TS Center Time (point in time where the energy received before this point is equal to the energy received after this point);

- L Loudness, Total Sound Level or Overall Level (measure of the room's ability to amplify sound from the source position). This measure is also denoted as $\mathrm{G}$ in the literature.

The method used is based on the integrated impulse-response method. A limitedbandwidth noise-burst is generated and transmitted into the church by a loudspeaker via an amplifier. The response of the room to the noise-burst (the impulse response) is then sampled from the RMS detector output of the sound level meter (time constant $5 \mathrm{~ms}$ ). A loudspeaker emitting short pulse noise bursts in $3 / 2$ octave frequency bands (to ensure that the received noise-burst is of $1 / 1$ octave bandwidth) was used as a sound source. The receiving system consisted of one 112" microphone and a sound level meter with a $1 / 1$ octave filter set. The measurement was controlled by software installed on a notebook computer. In each church, two locations were used for the loudspeaker (in front of the altar and in the centre of the main floor).The sound source was positioned $0.8 \mathrm{~m}$ above the floor, at a $45^{\circ}$ angle with the horizontal plane. Each measurement was calculated from an ensemble of 3 or 4 pulse responses in each position. Five receiver positions were, in average, used depending on the width of the church. The microphone, at each location, was placed $1.30 \mathrm{~m}$ above the floor. In total, approximately 8000 values were determined (all combinations of the 6 octave-frequency bands, 125 to $4 \mathrm{k} \mathrm{Hz}$, and source-receiver locations).The equipment used consisted of a sound level meter, 1/3-1/1 octave filter set, an analysis module Room Acoustics (B\&K-BZ7 109), a sound source and a 1/2" microphone. The notebook computer had application software Room Acoustics (B\&K-VP7 155) installed.

\subsection{Measurement Method for Subjective Parameters}

\subsubsection{Listeners and Music Sound Sources}

A group of 15 listeners was chosen to judge the quality of music throughout the churches. It was decided that a group of average and randomly selected listeners was not suitable for this study due to the need to have some acoustical knowledge 


\section{Room Acoustics and Environmental Noise}

concerning the parameters being tested. Therefore a group of 12 college students and 3 of their professors from the School of Music and the Performing Arts (Polytechnic Institute of Porto) was chosen.

To qualify their answers, all members of this group of listeners performed audiometric tests to evaluate their hearing capabilities. Audiograms from $125 \mathrm{~Hz}$ to 8 $\mathrm{kHz}$ and according to ISO R389/1964 and ANSI S3.6/1969 were performed giving results judged normal for all the members of the listeners' group.

In each church the listeners were seated in two similar locations named Position A (right hand seats of the centre of the longitudinal axis of the main floor) and Position $B$ (central seats at the rear main floor). A total of nearly 500 questionnaires were scored.

They listened to baroque and classic music for approximately ten minutes. The music used was a live performance from oboe and cello played first individually and then in ensemble. The pieces played were 3 or 4-minutes parts of the Bach's Suite No 3 (for the cello) and Telemann's Fantasy or Vivaldi's Sonata in G minor (for the oboe). After this, they played together the Duet for oboe and bassoon from Johann Gottlieb Naumann. Then they rated the acoustical qualities of the church on a questionnaire sheet. The scores from the questionnaires were entered into a computer spreadsheet and analyzed.

\subsubsection{Acoustic Evaluation Sheet}

The acoustic evaluation sheet used throughout the tests had ten semantic differential rating scales with seven points. The ten subjective acoustical parameters evaluated were:

- $\quad$ LOU - Loudness (the overall loudness or strength of the sound) from I (extremely weak) to 7 (extremely strong);

- CLA - Clarity (the degree to which notes are distinctly separated in time and clearly heard) from I (not clear enough) to 7 (extremely clear);

- $\quad$ REV - Reverberance (the persistence of sound in space) from 1 (totally dry) to 7 (too reverberant);

- $\quad$ INTM - Intimacy (the auditory impression of the apparent closeness of the orchestra) from 1 (absence of intimacy) to 7 (extremely intimate?;

- $\quad$ DIR - Direcotionality (the auditory impression that the sound comes from the axis of the sound source; importance of the direct sound field) from I (very bad) to 7 (excellent);

- $\quad$ ENV - Envelopment (the sense of being immersed in the sound or surrounded by it; importance of the reverberant field) from I (not surrounding at all) to 7 (extremely surrounding);

- $\quad$ BAL - Balarce (the relative levels of bass and treble frequencies) from I (totally unbalanced) to 7 (very well balanced);

- $\quad$ BGN - Background Noise (the sound heard other than from the source in the performance area) from 1 (not audible) to 7 (too loud);

- OIMP - Overall Impression 17 (the overall impression of the acoustical quality of the room) from I (very bad) to 7 (very good).

Remarks about Directionality. After pilot-tests, it was found that a new criterion (directionality) should be included together with the envelopment. In fact, the parameter 
envelopment was not easy for some listeners to fully comprehend and assess in churches. In this type of room the usually very large sound envelopment is not judged in the same way as that of many concert halls. Concert halls are usually smaller than churches and are generally considered more pleasant by listeners. However, in churches, the envelopment sensation is far above the maximum for music listening. Therefore, it was decided to include an easier measure to judge spatial aspects. This was named directionality and it attempts to evaluate not the spatial impression given by the reverberant field but the importance of the direct sound in the sensory experience. With this parameters the confusion partially disappeared as shown by some of the correlation analyses ${ }^{2}$.

\subsection{Architectural Parameters}

The thirteen Architectural Parameters used are shown in Table 4.

Table 4. Architectural Parameters used

\begin{tabular}{|c|c|c|c|}
\hline Term & Definition & Term & Definition \\
\hline ABST & Total Absorption $\left(\mathrm{m}^{2}\right)$ & LMAX & Length Maximum (m) \\
\hline \multirow[t]{2}{*}{ CABS } & Absorption Coefficient $\alpha$ & LNV & Length Nave (m) \\
\hline & (average value for all surfaces) & VTOT & Volume Total $\left(\mathrm{m}^{3}\right)$ \\
\hline ATOT & Area Total $\left(\mathrm{m}^{2}\right)$ & VNV & Volume Nave $\left(\mathrm{m}^{3}\right)$ \\
\hline ANV & Area Nave $\left(\mathrm{m}^{2}\right)$ & VTAT & $\begin{array}{l}\text { Height Total average }(\mathrm{m}) \\
\text { (= Volume total/Area total) }\end{array}$ \\
\hline HMAX & Height Maximum (m) & WNV & Width Nave (m) \\
\hline HNV & Height Nave (m) & WAVG & Width average (m) \\
\hline
\end{tabular}

TOTAL stands for the entire church including lateral chapels and main altar; NAVE stands for the entire church excluding lateral chapels and main altar.

\section{RESULTS}

\subsection{Relationships between Subjective Acoustic Parameters and Architectural Features}

This chapter presents the results concerning the relationships between subjective acoustic parameters and the architectural features. In this chapter all relationships are with respect to the averaged subjective data for each church (36 data points $=36$ churches).

Table 5 presents the absolute values for the linear correlation coefficients (Pearson coefficients) between subjective acoustic parameters and the thirteen architectural features. The best linear relationship exists between Intimacy and Total Volume $(|\mathrm{R}|=$ 0.87 ) demonstrating the importance that the church volume has regarding the feeling of intimacy. However, other important linear relationships were found:

$\begin{array}{ll}\text { Lo Mdness Iotal Absorption } & (|\mathrm{R}|=0.78) ; \\ \text { Clarity/NaveVolume } & (|\mathrm{R}|=0-71) ; \\ \text { Echoes/Maximum Height } & (|\mathrm{R}|=0.75) ; \\ \text { Directionality/Nave Volume } & (|\mathrm{R}|=0.73) ; \\ \text { Balance/Nave Height } & (|\mathrm{R}|=0.79) ; \\ \text { Overall Impression/Total Volume } & (|\mathrm{R}|=0.75)\end{array}$


Tables 6 and 7 present the best simple models (those with $R^{2}>055$ ), linear or nonlinear, of nearly 400 tested between subjective acoustical parameters and architectural features. Table 6 presents the models ordered by architectural feature and Table 7 presents them sorted by subjective acoustic parameter.

Table 5. Absolute values for linear correlation coefficients $(|\mathbf{R}|)$ between subjective acoustical parameters and architectural features. $|R|>0.85$ are bold faced

\begin{tabular}{lcccccccccc}
\hline$|\mathbf{R}|$ & BGN & LOU & CLA & REV & ECH & INTM & DIR & ENV & BAL & OIMP \\
\hline VTOT & 0.168 & 0.769 & 0.701 & 0.642 & 0.690 & $\mathbf{0 . 8 7 3}$ & 0.721 & 0.317 & 0.697 & 0.751 \\
VNV & 0.188 & 0.724 & 0.711 & 0.661 & 0.706 & $\mathbf{0 . 8 5 4}$ & 0.728 & 0.271 & 0.705 & 0.749 \\
ATOT & 0.064 & 0.741 & 0.693 & 0.652 & 0.620 & $\mathbf{0 . 8 7 0}$ & 0.692 & 0.291 & 0.621 & 0.712 \\
ANV & 0.094 & 0.659 & 0.688 & 0.669 & 0.613 & 0.821 & 0.681 & 0.212 & 0.592 & 0.683 \\
LMAX & 0.175 & 0.779 & 0.671 & 0.618 & 0.603 & $\mathbf{0 . 8 6 1}$ & 0.688 & 0.241 & 0.615 & 0.681 \\
LNV & 0.196 & 0.739 & 0.686 & 0.659 & 0.621 & 0.844 & 0.718 & 0.235 & 0.618 & 0.688 \\
HMAX & 0.206 & 0.657 & 0.670 & 0.620 & 0.747 & 0.737 & 0.681 & 0.095 & 0.743 & 0.678 \\
HNV & 0.269 & 0.678 & 0.670 & 0.590 & 0.733 & 0.755 & 0.673 & 0.175 & 0.789 & 0.681 \\
WNV & 0.148 & 0.353 & 0.533 & 0.559 & 0.495 & 0.543 & 0.465 & 0.000 & 0.466 & 0.476 \\
WAVG & 0.116 & 0.461 & 0.625 & 0.641 & 0.570 & 0.641 & 0.564 & 0.043 & 0.515 & 0.578 \\
VTAT & 0.324 & 0.694 & 0.637 & 0.596 & 0.725 & 0.755 & 0.668 & 0.172 & 0.773 & 0.663 \\
ABST & 0.129 & 0.783 & 0.589 & 0.522 & 0.505 & 0.827 & 0.592 & 0.431 & 0.581 & 0.630 \\
CBAS & 0.013 & 0.175 & 0.198 & 0.201 & 0.257 & 0.051 & 0.191 & 0.290 & 0.158 & 0.187
\end{tabular}

Table 6. Best simple models between subjective acoustical parameters and architectural features ordered by architectural feature. $R^{2}>0.75$ are bold faced

\begin{tabular}{|c|c|}
\hline Equations & $\mathbf{R}^{2}$ (variance explained) \\
\hline OIMP $=5.622-0.23 \times 10^{-3}$ VTOT $+0.45 \times 10^{-8}$ VTOT $^{2}$ & 0.518 \\
\hline $\mathrm{LOU}=5.257-7.5 \times 10^{-5} \mathrm{VTOT}$ & 0.591 \\
\hline $\mathrm{INTM}=5.410-1.6 \times 10^{-4} \mathrm{VTOT}$ & 0.763 \\
\hline OIMP $=5.636-0.29 \times 10^{-3} \mathrm{VNV}-0.74 \times 10^{-8} \mathrm{VNV}^{2}$ & 0.577 \\
\hline $\mathrm{INTM}=10.447-0.747 \log \mathrm{VNV}$ & 0.732 \\
\hline INTM $=5.751-2.9 \times 10^{-3}$ ATOT & 0.756 \\
\hline $\mathrm{INTM}=5.845-4.8 \times 10^{-3} \mathrm{ANV}+2 \times 10^{-6} \mathrm{ANV}^{2}$ & 0.679 \\
\hline $\mathrm{LOU}=5.883-0.031 \mathrm{LMAX}$ & 0.607 \\
\hline $\mathrm{INTM}=6.666-0.064 \mathrm{LMAX}$ & 0.742 \\
\hline $\mathrm{INTM}=6.235-0.055 \mathrm{LNV}-5.5 \times 10^{-4} \mathrm{LNV}^{2}$ & 0.716 \\
\hline $\mathrm{ECH}=0.719+0.101 \mathrm{HMAX}$ & 0.559 \\
\hline $\mathrm{BAL}=7.152-0.138 \mathrm{HMAX}+1.5 \times 10^{-3} \mathrm{HMAX}^{2}$ & 0.577 \\
\hline $\mathrm{INTM}=7.237-0.298 \mathrm{HNV}+5.3 \times 10^{-3} \mathrm{HNV}^{2}$ & 0.597 \\
\hline $\mathrm{BAL}=6.693-0.075 \mathrm{HNV}-1.5 \times 10^{-3} \mathrm{HNV}^{2}$ & 0.627 \\
\hline $\mathrm{INTM}=7.366-0.339 \mathrm{VTAT}+6.7 \times 10^{-3} \mathrm{VTAT}^{2}$ & 0.593 \\
\hline $\mathrm{BAL}=6.717-0.079 \mathrm{VTAT}-2.1 \times 10^{-3} \mathrm{VTAT}^{2}$ & 0.601 \\
\hline $\mathrm{LOU}=5.377-3.8 \times 10^{-3} \mathrm{ABST}$ & 0.613 \\
\hline INTM $=5.908-0.013 \mathrm{ABST}+1.4 \times 10^{-5} \mathrm{ABST}^{2}$ & 0.718 \\
\hline
\end{tabular}


Table 7. Best simple models between subjective acoustical parameters and architectural features sorted by subjective acoustical parameter. $\mathbf{R}^{2}>\mathbf{0 . 7 5}$ are bold faced

\begin{tabular}{|c|c|}
\hline Equations & $\mathbf{R}^{2}$ (variance explained) \\
\hline $\mathrm{LOU}=5.257-7.5 \times 10^{-5} \mathrm{VTOT}$ & 0.591 \\
\hline LOU $=5.883-0.031$ LMAX & 0.607 \\
\hline $\mathrm{LOU}=5.377-3.8 \times 10^{-3} \mathrm{ABST}$ & 0.613 \\
\hline $\mathrm{ECH}=0.719+0.101 \mathrm{HMAX}$ & 0.559 \\
\hline $\mathrm{INTM}=5.410-1.6 \times 10^{-4} \mathrm{VTOT}$ & 0.763 \\
\hline $\mathrm{INTM}=10.447-0.747 \log \mathrm{VNV}$ & 0.732 \\
\hline INTM $=5.751-2.9 \times 10^{-3}$ ATOT & 0.756 \\
\hline $\mathrm{INTM}=5.845-4.8 \times 10^{-3} \mathrm{ANV}+2 \times 10^{-6} \mathrm{ANV}^{2}$ & 0.679 \\
\hline INTM $=6.666-0.064$ LMAX & 0.742 \\
\hline $\mathrm{INTM}=6.235-0.055 \mathrm{LNV}-5.5 \times 10^{-4} \mathrm{LNV}^{2}$ & 0.716 \\
\hline $\mathrm{INTM}=7.237-0.298 \mathrm{HNV}+5.3 \times 10^{-3} \mathrm{HNV}^{2}$ & 0597 \\
\hline $\mathrm{INTM}=7.366-0.339 \mathrm{VTAT}+6.7 \times 10^{-3} \mathrm{VTAT}^{2}$ & 0.593 \\
\hline INTM= $5.908-0.013 \mathrm{ABST}+1.4 \times 10^{-5} \mathrm{ABST}^{2}$ & 0.718 \\
\hline $\mathrm{BAL}=7.152-0.138 \mathrm{HMAX}+1.5 \times 10-3 \mathrm{HMAX}^{2}$ & 0.577 \\
\hline $\mathrm{BAL}=6.693-0.075 \mathrm{HNV}-1.5 \times 103 \mathrm{HNV}^{2}$ & 0.627 \\
\hline $\mathrm{BAL}=6.717-0.079 \mathrm{VTAT}-2.1 \times 103 \mathrm{VTAT}^{2}$ & 0.601 \\
\hline OIMP $=5.622-0.23 \times 10-3$ VTOT $+0.45 \times 10-8$ vTOT $^{2}$ & 0.578 \\
\hline OIMP $=5.636-0.29 \times 10-3 \mathrm{VNV}-0.74 \times 108 \mathrm{VNV}^{2}$ & 0.577 \\
\hline
\end{tabular}

Figure 1 shows the graphical representation of the best simple models, presented in Tables 6 and 7. The best models $\left(\mathrm{R}^{2}=0.76\right)$ are those relating Intimacy/Total Volume and Intimacy/Total Area.

With the goal of trying to find a better model that can explain the relationships between subjective acoustical parameters and architectural features, general linear models were calculated. The operational procedure was to use forward or backward stepwise modeling with an a-to-enter (or to-remove) equal to 0.15. The accuracy of the models was judged primarily by their R 2 which represents the percentage of variance explained and secondarily by the standard error of the estimate which represents the magnitude of differences between estimated and observed values. The general linear models are presented in Table 8.

The best general linear models were found for Intimacy $\left(\mathrm{R}^{2}=0.87\right)$ and Loudness $\left(\mathrm{R}^{2}=0.77\right)$ The auditory impressions of the apparent closeness of the orchestra and the overall loudness of the sound seem to be connected to the architectural features of the churches.

The subjective acoustical parameters with the worst adjustment model is the Background Noise $\left(\mathrm{R}^{2}=035\right)$. This can be easily explained because background noise is temporary and depends on the extraneous noise. Envelopment also presented a low $\mathrm{R}^{2}(0.43)$ due to the fact that this parameter was not fully assessed in churches (as seen in 2.4.2). 
Room Acoustics and Environmental Noise
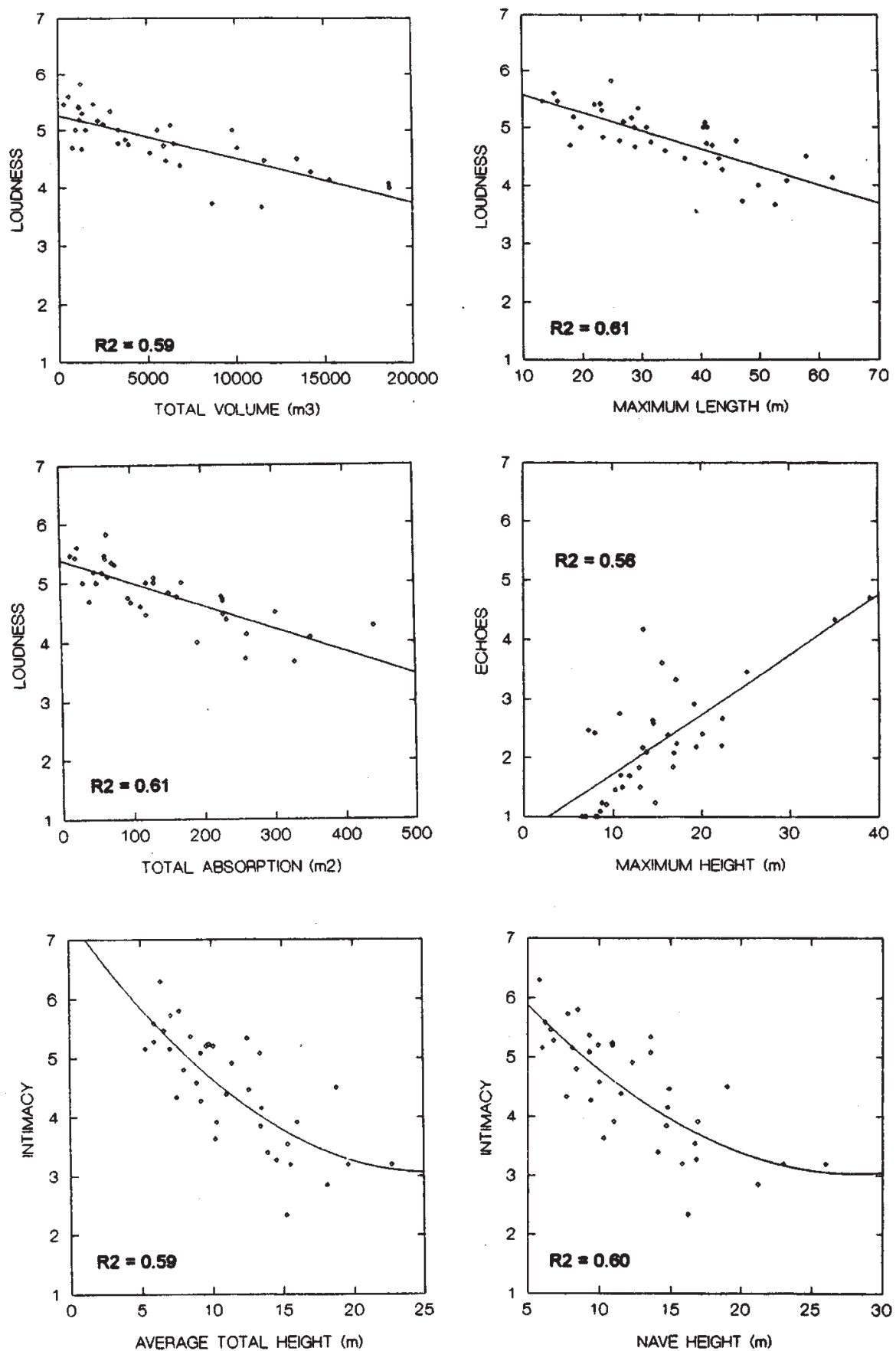

Figure 1. Mean values of subjective acoustic parameters for each church (36 points $=36$ churches) plotted vs. the architectural parameters with regression models. 

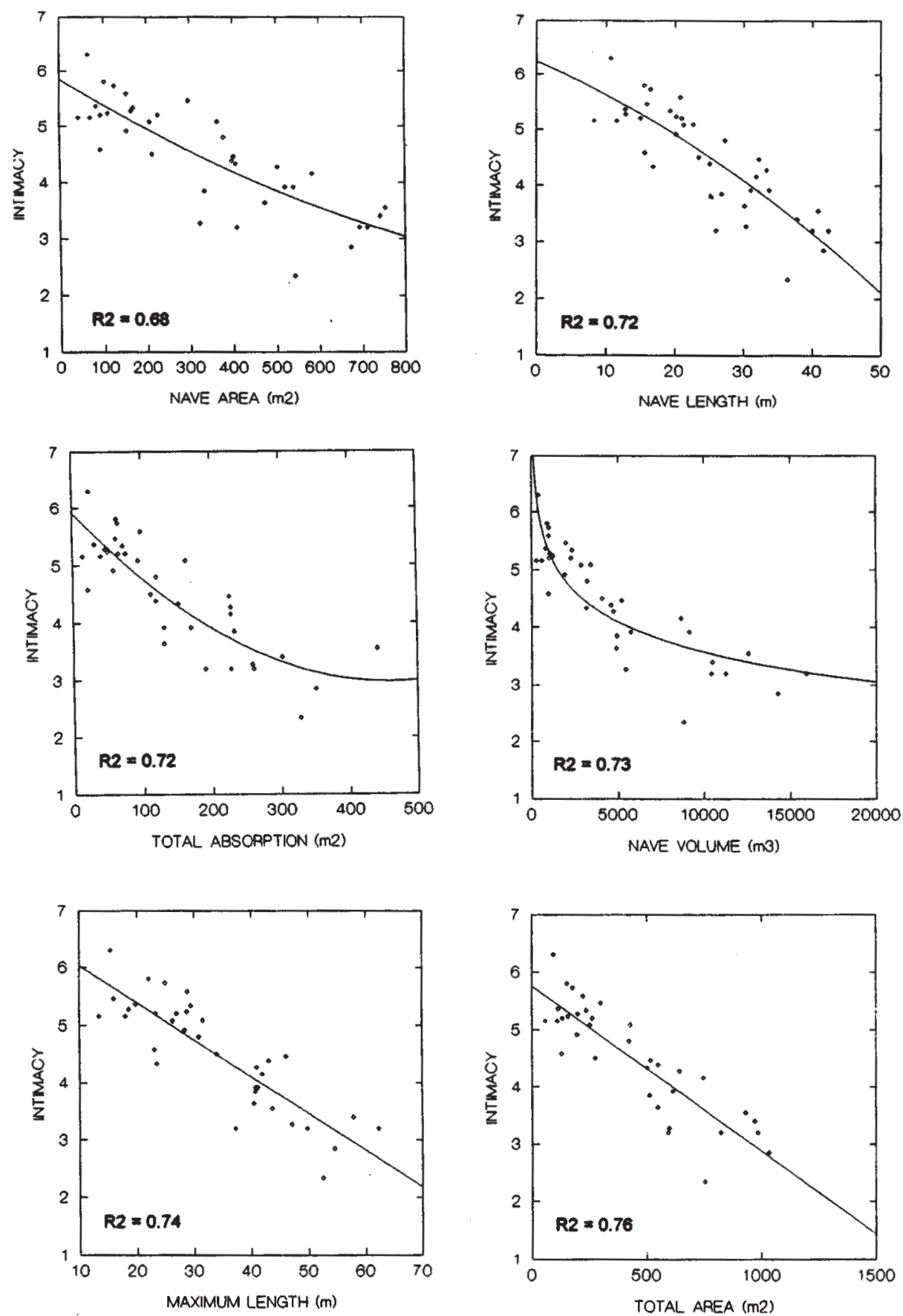

Figure 1 (cont.). Mean values of subjective acoustic parameters for each church (36 points $=36$ churches) plotted vs. the architectural parameters with regression models. 
Room Acoustics and Environmental Noise
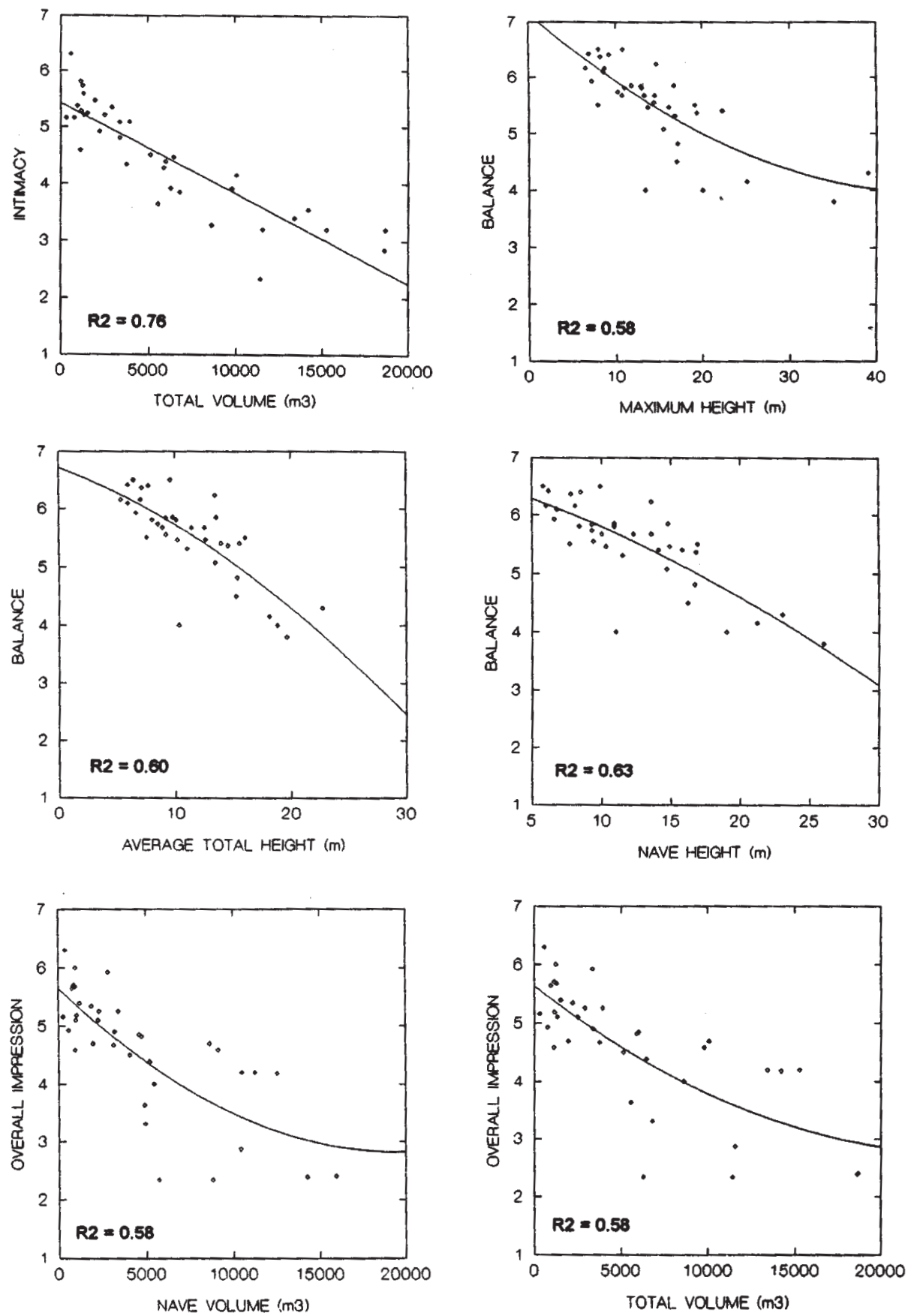

Figure 1 (cont.). Mean values of subjective acoustic parameters for each church (36 points $=36$ churches) plotted vs. the architectural parameters with regression models. 
The architectural parameter CABS (average absorption coefficient a) appears as variable in almost all the above general linear models indicating that this architectural feature can be important in predicting the subjective acoustic response of churches. The average width of churches (WAVG) performs almost as well as CABS in that function.

Table 8. Relationships between subjective acoustic parameters and architectural parameters (general linear models). $R^{2}>0.75$ are bold faced

\begin{tabular}{|c|c|c|}
\hline General Linear Model Equations & $\begin{array}{l}\text { Standard } \\
\text { Error of Estimate }\end{array}$ & $\mathbf{R}^{2}$ \\
\hline 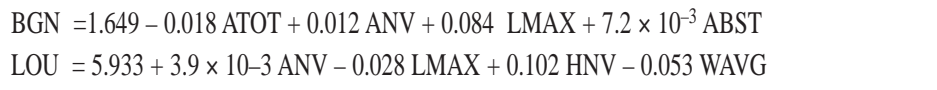 & 0.95 & 0.35 \\
\hline$-0.097 \mathrm{VTAT}-3.1 \times 10-3 \mathrm{ABST}$ & 0.28 & 0.77 \\
\hline $\mathrm{CLA}=6.833-0.116 \mathrm{HNV}-0.100 \mathrm{WAVG}+10.932 \mathrm{CABS}$ & 0.80 & 0.61 \\
\hline $\mathrm{REV}=1.179-8.2 \times 10^{-3} \mathrm{ANV}+0.179 \mathrm{LNV}+0.220 \mathrm{WAVG}-17.090 \mathrm{CABS}$ & 0.75 & 0.63 \\
\hline $\begin{array}{l}\mathrm{ECH}=-0.284-5.6 \times 10^{-3} \mathrm{ANV}+0.100 \mathrm{LNV}+0.062 \mathrm{HMAX}+0.142 \mathrm{WAVG}-12.929 \mathrm{CABS} \\
\mathrm{INTM}=5.858+3.6 \times 10^{-3} \mathrm{ATOT}-0.048 \mathrm{LMAX}-0.060 \mathrm{WNV}-7.3 \times 10^{-3}\end{array}$ & 0.59 & 0.69 \\
\hline $\mathrm{ABST}+14.86 \mathrm{CABS}$ & 0.39 & 0.87 \\
\hline $\mathrm{DIR}=6.833+4.0 \times 10^{-3} \mathrm{ANV}-0.100 \mathrm{LNV}-0.041 \mathrm{HNV}-0.095 \mathrm{WAVG}+10.831 \mathrm{CABS}$ & 0.52 & 0.66 \\
\hline $\mathrm{ENV}=4.265+0.027 \mathrm{LMAX}+0.030 \mathrm{HMAX}-6.893 \mathrm{CABS}$ & 0.39 & 0.43 \\
\hline $\mathrm{BAL}=6.881-0.107 \mathrm{HNV}-0.036 \mathrm{WNV}+5.819 \mathrm{CABS}$ & 0.43 & 0.70 \\
\hline OIMP $=5.561+6.0 \times 10^{-3}$ ATOT -0.048 LMAX -0.114 WAVG $-8.5 \times 10^{-3}$ & & \\
\hline $\mathrm{ABST}+22.672 \mathrm{CABS}$ & 0.69 & 0.65 \\
\hline
\end{tabular}

\subsection{Relationships between Subjective and Objective Acoustical Parameters}

\subsubsection{Averaging Method}

The following analyses used averaged data for each church. Seven averaging methods were tested using the average of 2,3,4 or 6 octave frequency-bands to obtain a single value for each objective room acoustic parameter and for each church. These options were named M I to M7 and are indicated in Table 9.

Table 9. Seven options of frequency averaging options

\section{Code Definition}

M1 Average of all 6 frequency bands

M2 Average of the 2 highest frequency bands

M3 Average of the 4 lowest frequency bands

M4 Average of the 4 highest frequency bands

M5 Average of 4 medium frequency hands

M6 Average of 3 medium frequency bands

M7 Average of 2 medium frequency bands
(125 to $4000 \mathrm{~Hz}$ octave bands)

(2000 and $4000 \mathrm{~Hz}$ octave bands)

(125 to $1000 \mathrm{~Hz}$ octave bands)

(500 to $4000 \mathrm{~Hz}$ octave bands)

(250 to $2000 \mathrm{~Hz}$ octave bands)

(500, 1000 and $2000 \mathrm{~Hz}$ octave bands)

(500 and $1000 \mathrm{~Hz}$ octave bands) 


\section{Room Acoustics and Environmental Noise}

Regression analyses were performed with all these seven averaging options to check for their influence in the results6 The differences among them were found to be small. Nevertheless the option M7 (500 and 1k Hz) appeared the most suitable for this type of analysis, giving the highest percentage of variance explained for almost all situations. This averaging option was then used in the following studies.

\subsubsection{Simple Models}

Using the frequency averaging option M7 (average of 500 and $1000 \mathrm{~Hz}$ octave band data) stated above, linear and non linear models were used for each of the ten subjective acoustic parameters regarding their relationships with the six objective room acoustic parameters. Table 10 presents the equations for some of the best models found. The variance of the Echoes and Reverberance can be largely explained with just one of the six objective room acoustic parameters $\left(\mathrm{R}^{2}>0.85\right)$. For Background Noise, Loudness, Intimacy, Envelopment and Balance the percentage of variance explained by just one objective room acoustic parameter is not very significant $\left(\mathrm{R}^{2}<0.55\right)$.

The relationship Reverberance/RT with a $\mathrm{R}^{2}=0.845$ confirms that $\mathrm{RT}$ is an objective measure of the sense of reverberance. However, using EDT the $\mathrm{R}^{2}$ increases to 0.854 making this objective room acoustic measure a little more suited to the feeling of reverberance.

The relationship Clarity/C80 with a $\mathrm{R}^{2}=0.72$ also confirms the suitability of $\mathrm{C} 80$ to objectively represent the sense of clarity. Nevertheless the EDT (and RT) are even better in performing that role $\left(\mathrm{R}^{2}=0.83\right)$. This confirms the ideas presented by Chiang ${ }^{4,5}$. The relationship Overall Impression/EDT $\left(\mathrm{R}^{2}=0.74\right)$ also confirms a similar consideration of this pair of parameters by Cervone ${ }^{3}$.

The relationship Loudness $/ \mathrm{L}$ with a $\mathrm{R}^{2}=0.60$ does not fulfill the expectations regarding their relationship.

The Figure 2 presents some of the best or more significant relationships found between subjective and objective acoustic parameters using the frequency averaging option M7 (500 and 1k Hz).

\subsubsection{General Linear Models}

With the goal of trying to find better models that can explain the relationships between subjective and objective acoustical parameters, general linear models were calculated. Again the operational procedure was to use forward or backward stepwise modeling with an $\alpha$-to-enter (or to-remove) equal to 0.15 . The accuracy of the models was judged primarily by their $\mathrm{R}^{2}$ which represents the percentage of variance explained and secondarily by the standard error of the estimate which represents the magnitude of differences between estimated and observed values. The general linear models are presented in Table 11 together with indication of which frequency averaging option (Mi) gtives the best model.

As seen in Table 11 almost all subjective parameters have suitable models except Background Noise and Envelopment $\left(\mathrm{R}^{2}<0.70\right)$. The objective parameter RT appears as variable in almost all general linear models indicating that this measure can be very important in predicting the subjective acoustic response of churches. EDT and L perform almost as well as RT in that function. C80 however, does not appear in the models, perhaps revealing that it is not a significant measure in predicting subjective acoustic responses in churches. 

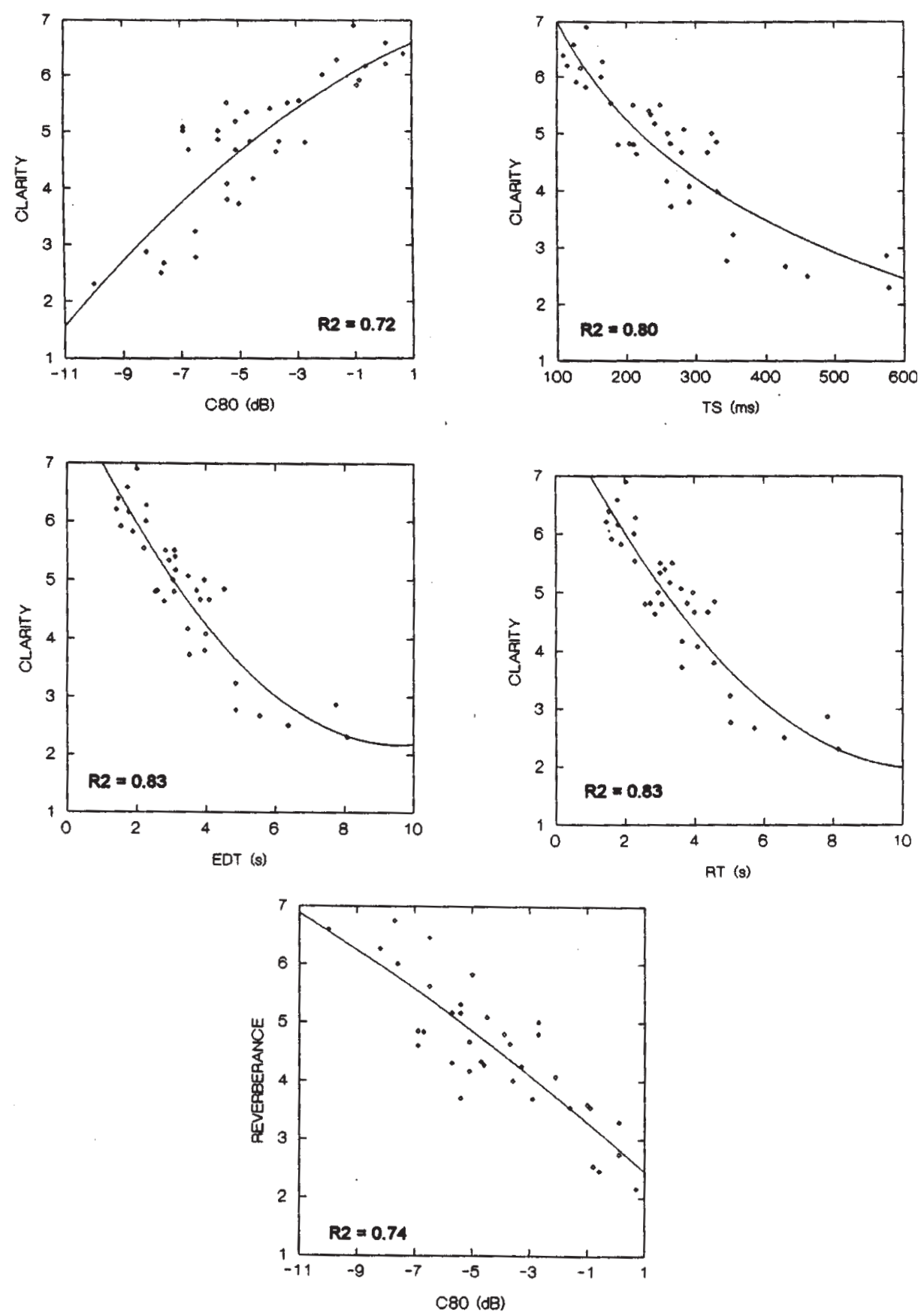

Figure 2. Relationships between subjective and objective acoustic parameters using the frequency averaging option M7 (500 and 1k Hz) 
Room Acoustics and Environmental Noise
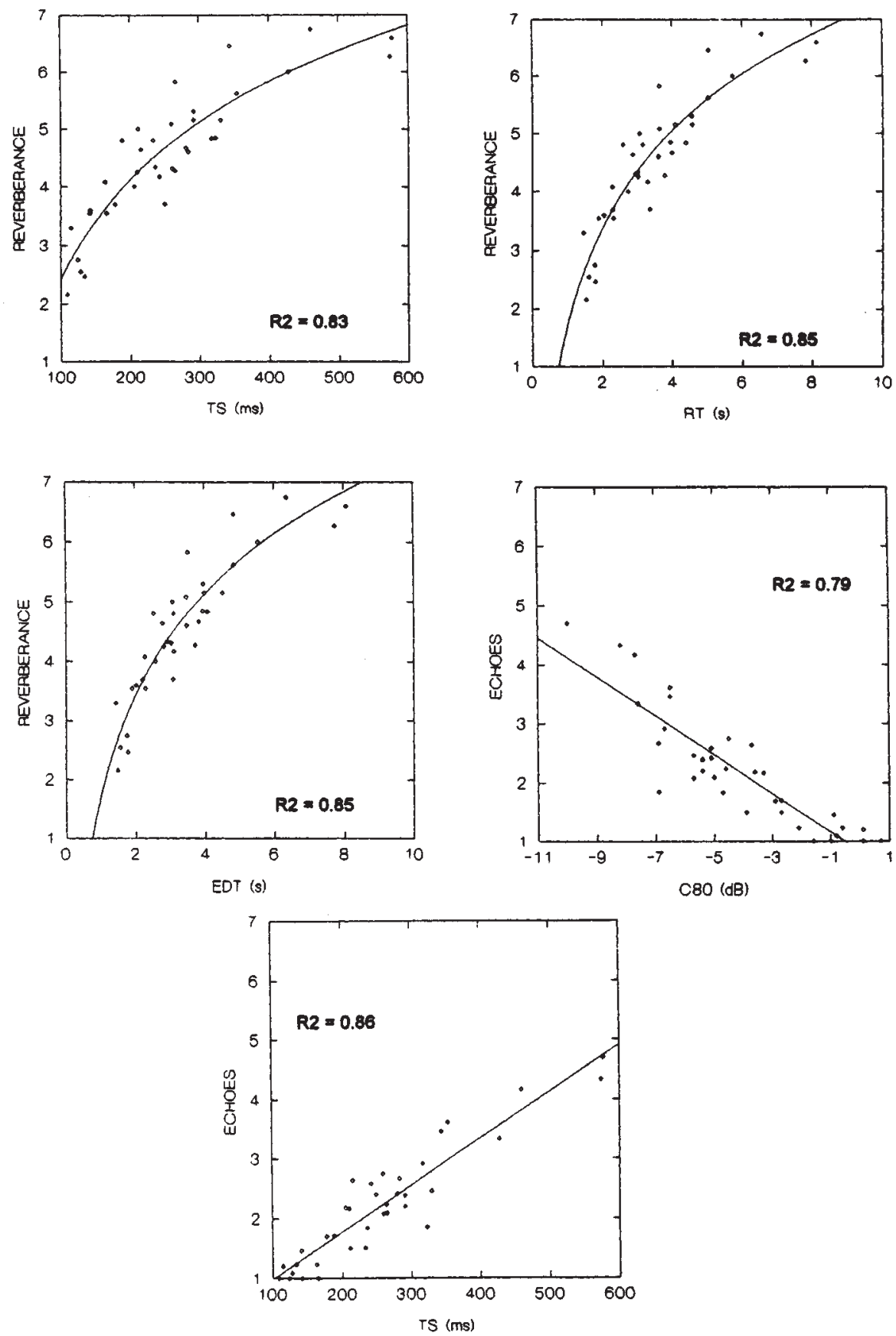

Figure 2 (cont.). Relationships between subjective and objective acoustic parameters using the frequency averaging option M7 (500 and 1k Hz) 

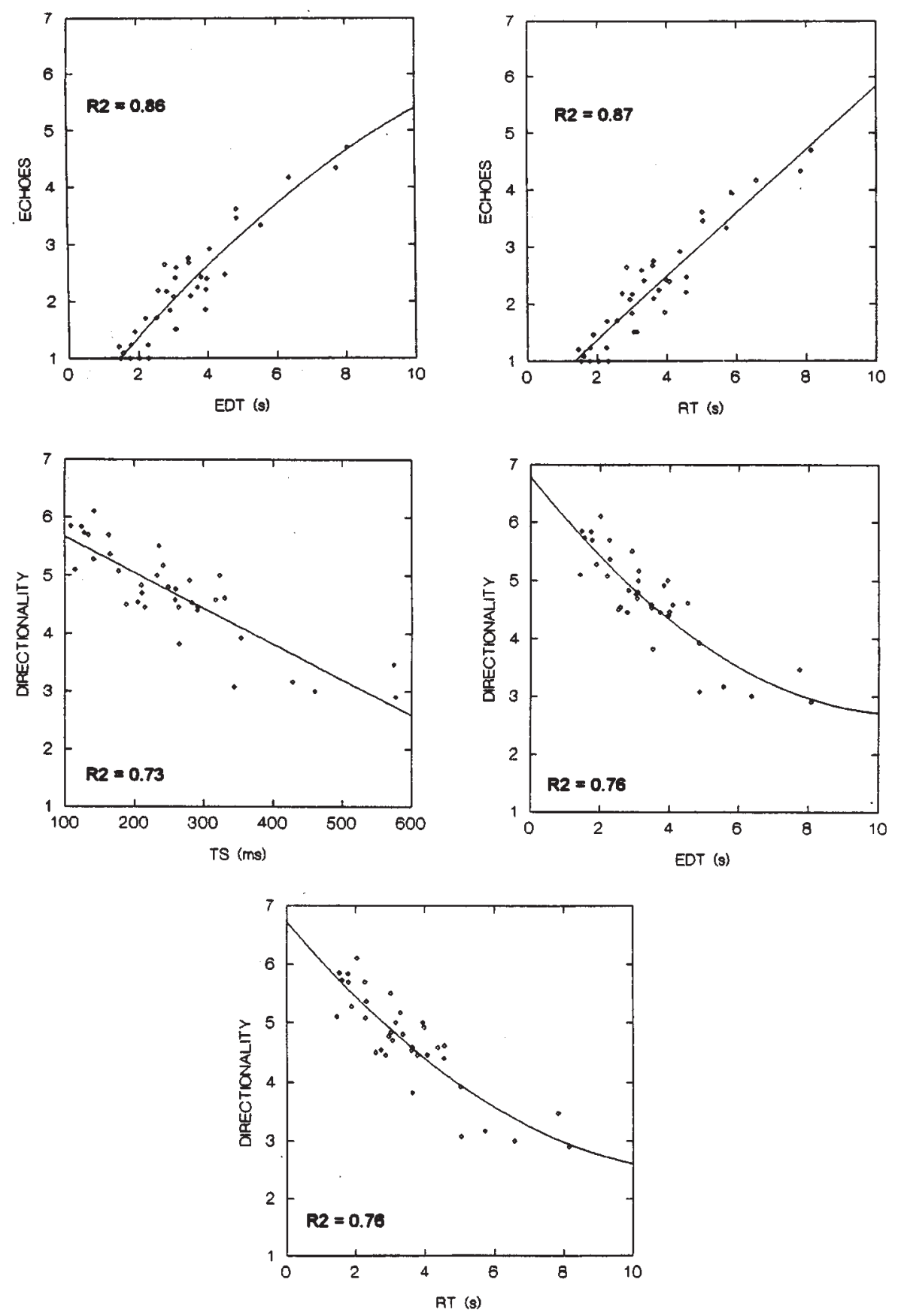

Figure 2 (cont.). Relationships between subjective and objective acoustic parameters using the frequency averaging option M7 (500 and $1 \mathrm{k} \mathrm{Hz})$ 
Room Acoustics and Environmental Noise
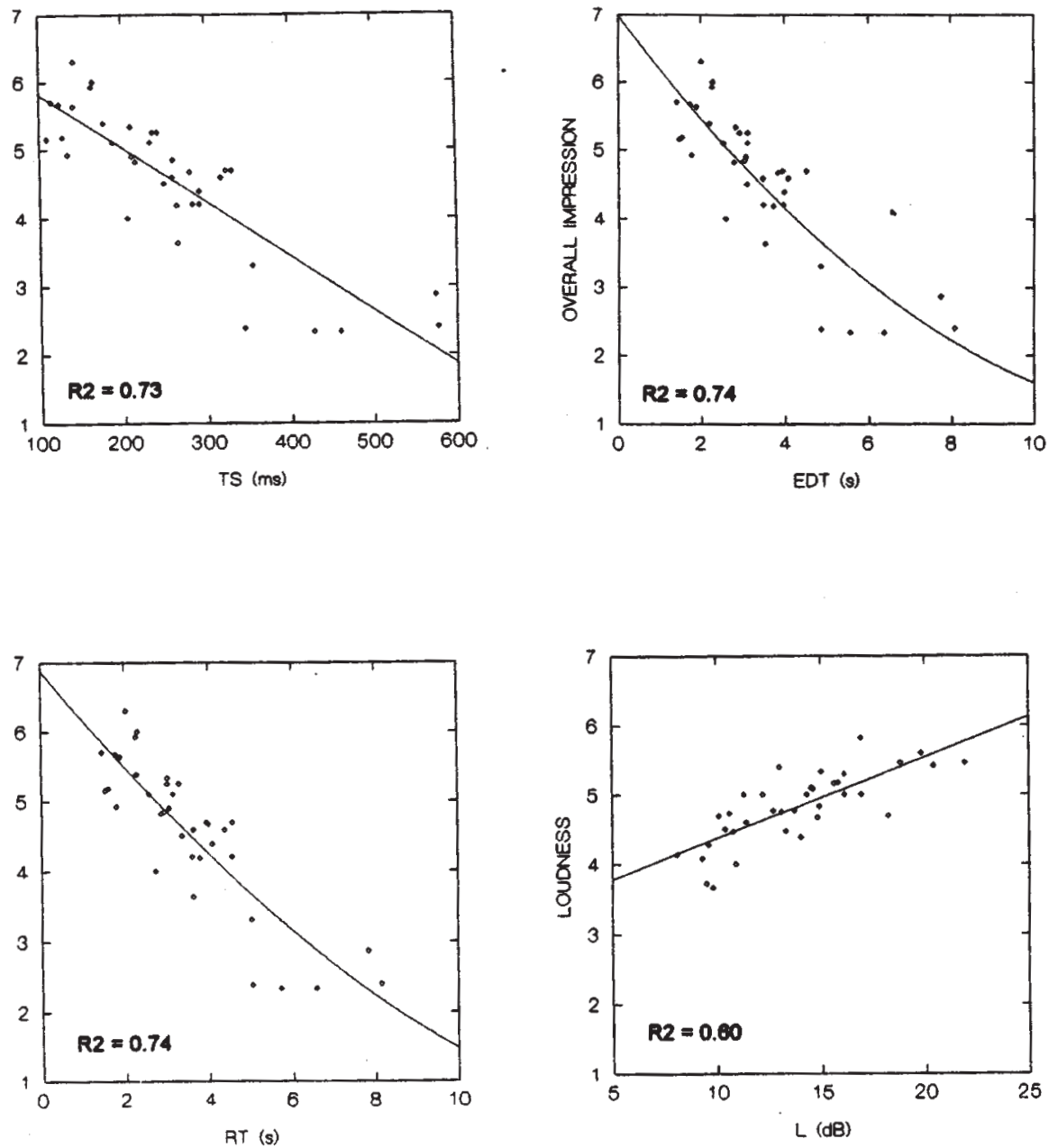

Figure 2 (cont.). Relationships between subjective and objective acoustic parameters using the frequency averaging option M7 (500 and $1 \mathrm{k} \mathrm{Hz}$ ) 
Table 10. Most significant relationships between subjective and objective acoustic parameters (using the frequency averaging method M7 - 500/lk Hz). $R^{2}>0.75$ are bold faced.

\begin{tabular}{ll}
\hline Equations (simple methods) & $\mathbf{R}^{2}$ (variance explained) \\
\hline $\mathrm{CLA}=6.330+0.265 \mathrm{C} 80-0.015 \mathrm{C}^{2} 0^{2}$ & 0.724 \\
$\mathrm{CLA}=18.717-2.542 \log \mathrm{TS}$ & $\mathbf{0 . 7 9 8}$ \\
$\mathrm{CLA}=8.230-1.265 \mathrm{EDT}+0.066 \mathrm{EDT}^{2}$ & $\mathbf{0 . 8 2 9}$ \\
$\mathrm{CLA}=8.108-1.162 \mathrm{RT}+0.055 \mathrm{RT} 2$ & $\mathbf{0 . 8 3 4}$ \\
$\mathrm{REV}=2.876-0.421 \mathrm{C} 80-5.1 \times 10^{-3} \mathrm{C}^{2} 0^{2}$ & 0.740 \\
$\mathrm{REV}=8.902+2.459 \log \mathrm{TS}$ & $\mathbf{0 . 8 2 5}$ \\
$\mathrm{REV}=1.709+2.4171$ og RT & $\mathbf{0 . 8 4 5}$ \\
$\mathrm{REV}=1.741+2.451 \log \mathrm{EDT}$ & $\mathbf{0 . 8 5 4}$ \\
$\mathrm{ECH}=0.829-0.329 \mathrm{C} 80$ & $\mathbf{0 . 7 8 8}$ \\
$\mathrm{ECH}=0.044+0.744 \mathrm{EDT}-0.020 \mathrm{EDT}^{2}$ & $\mathbf{0 . 8 6 4}$ \\
$\mathrm{ECH}=0.192+7.9 \times 10^{-3} \mathrm{TS}$ & $\mathbf{0 . 8 6 4}$ \\
$\mathrm{ECH}=0.023+0.682 \mathrm{RT}-0.014 \mathrm{RT}^{2}$ & $\mathbf{0 . 8 7 2}$ \\
$\mathrm{DIR}=6.281-6.1 \times 10^{-3} \mathrm{TS}$ & 0.729 \\
$\mathrm{DIR}=6.798-0.761 \mathrm{EDT}+0.035 \mathrm{EDT}^{2}$ & $\mathbf{0 . 7 6 0}$ \\
$\mathrm{DIR}=6.714-0.693 \mathrm{RT}+0.028 \mathrm{RT}^{2}$ & $\mathbf{0 . 7 6 2}$ \\
$\mathrm{OIMP}=6.606-7.9 \times 10^{-3} \mathrm{TS}$ & 0.725 \\
$\mathrm{OIMP}=6.991-0.826 \mathrm{LDT}+0.029 \mathrm{EDT}^{2}$ & 0.735 \\
$\mathrm{OIMP}=6.890-0.744 \mathrm{RT}-0.020 \mathrm{RT}^{2}$ & 0.742 \\
$\mathrm{LOU}=2.100+0.196 \mathrm{~L}$ & 0.597
\end{tabular}

\section{CONCLUDING REMARKS}

The scope of this work is to investigate the subjective acoustical behavior of churches, how it relates with other parameters and to determine simple formulae to predict acoustical parameters by the use of elementary architectural features and objective room acoustic parameters.

This work continues and develops previous studies in this field and has its basis in subjective and objective acoustical analyses done on field measurements in a survey of 36 Catholic churches in Portugal that were built in the last 14 centuries.

This is an interim paper on work in progress, and some results are perceived as a basis for further study. However, there are several conclusions that can be drawn. The results of this research indicate that statistically significant relationships between subjective and objective criteria can be found in churches.

Architectural features that are important in defining the overall acoustical impression in churches were identified. Total Volume was found to be the most important of these, and gave the best fit between subjective acoustical parameters and architectural measures for Intimacy/Total Volume. Intimacy and Loudness were the only subjective acoustical parameters where the influence of the architectural parameters was statistically significant in the listeners' response. 
Room Acoustics and Environmental Noise

Table 11. Relationships between Subjective and Objective Acoustic Parameters (General Linear Models) with the frequency averaging option used. $\mathbf{R}^{2}>0.75$ are bold faced

\begin{tabular}{|c|c|c|c|c|}
\hline \multicolumn{2}{|c|}{$\begin{array}{l}\text { General Linear Model Equations } \\
\text { Estimate } \\
\text { (StD of } \\
\text { residuals) }\end{array}$} & $\begin{array}{l}\text { St Error of } \\
\text { (variance } \\
\text { explained) }\end{array}$ & $\begin{array}{l}\text { R2 } \\
\text { option } \\
\text { Mi }\end{array}$ & Averaging \\
\hline \multicolumn{2}{|c|}{ BGN (no suitable model) } & - & - & - \\
\hline LOU & $=3.630-1.620 \mathrm{RT}+1.640 \mathrm{EDT}-0.099 \mathrm{~L}$ & 0.30 & 0.70 & M1 \\
\hline CLA & $=6.336-0.629 \mathrm{RT}+0.052 \mathrm{~L}$ & 0.52 & 0.83 & M7 \\
\hline REV & $=5.118+2.169 \mathrm{EDT}-7.666 \mathrm{D}-0.025 \mathrm{TS}$ & 0.48 & 0.85 & M7 \\
\hline $\mathrm{ECH}$ & $=0.987+1.615$ RT- $1.161 \mathrm{EDT}-2.071 \mathrm{D}$ & 0.34 & 0.89 & M6 \\
\hline INTM & $=3.387-2.433 \mathrm{RT}+2.243 \mathrm{EDT}+0.150 \mathrm{~L}$ & 0.46 & 0.79 & M1 \\
\hline DIR & $=4.858-1.067 \mathrm{RT}+0.010 \mathrm{TS}+0.071 \mathrm{~L}$ & 0.39 & 0.80 & M1 \\
\hline ENV & $=4.276-1.719 \mathrm{RT}+1.798 \mathrm{EDT}-3.237 \mathrm{D}+0.069 \mathrm{~L}$ & 0.36 & 0.51 & M1 \\
\hline BAL & $=6.050-2.342 \mathrm{RT}+2.077 \mathrm{EDT}+0.049 \mathrm{~L}$ & 0.36 & 0.78 & M3 \\
\hline OIMP & $=5.379-3.175 \mathrm{RT}+2.776 \mathrm{EDT}+0.066 \mathrm{~L}$ & 0.49 & 0.81 & M1 \\
\hline RT & $\begin{aligned}= & 6.192+0.140 \mathrm{BGN}+0.733 \mathrm{REV}+1.058 \mathrm{ECH}+ \\
& 0.353 \mathrm{INTM}+1.235 \mathrm{DIR}-0.870 \text { OIMP }\end{aligned}$ & $0.48 \mathrm{~s}$ & 0.92 & M1 \\
\hline EDT & $\begin{aligned}= & 4.342+0.122 \mathrm{BGN}+0.692 \mathrm{REV}+0.890 \mathrm{ECH}+ \\
& 0.954 \text { DIR }-0.513 \text { OIMP }\end{aligned}$ & $0.47 \mathrm{~s}$ & 0.91 & M6 \\
\hline $\mathrm{C} 80$ & $\begin{aligned}= & 23.82-0.278 \text { BGN }-1.195 \text { CLA }-2.102 \text { REV }-1.853 \mathrm{ECH}- \\
& 1.120 \text { INTM }-2.734 \text { DIR }-0.804 \text { ENV + 0.913 OIMP }\end{aligned}$ & $0.84 \mathrm{~dB}$ & 0.92 & M5 \\
\hline $\mathrm{D}$ & $\begin{aligned}= & 1.168-0.012 \mathrm{BGN}-0.059 \mathrm{REV}-0.058 \mathrm{ECH}+ \\
& 0.048 \mathrm{INTM}-0.116 \mathrm{DIR}-0.044 \mathrm{ENV}\end{aligned}$ & 0.04 & 0.83 & M5 \\
\hline TS & $\begin{aligned}= & 521.9+36.46 \mathrm{CLA}+55.45 \mathrm{REV}+70.51 \mathrm{ECH}+ \\
& 72.98 \mathrm{DIR}+26.28 \mathrm{ENV}-64.22 \mathrm{OIMP}\end{aligned}$ & $32 \mathrm{~ms}$ & 0.91 & M1 \\
\hline $\mathrm{L}$ & $=14.06+3.949 \mathrm{LOU}+2.465 \mathrm{INTM}+3.200 \mathrm{DIR}-3.778$ OIMP & $1.80 \mathrm{~dB}$ & 0.77 & M1 \\
\hline
\end{tabular}

The architectural parameter CABS (average absorption coefficient a) appears as variable in almost all the general linear models indicating that this architectural feature can be important in predicting the subjective acoustic response of churches. The average width of churches $(W A V G)$ performs almost as well as $C A B S$ in that function.

In general, some of the thirteen architectural parameters tested can be used in general linear models to explain from $61 \%$ to $87 \%$ of the variance of the eight main subjective acoustic parameters studied.

The best fit between subjective acoustical parameters and objective acoustical parameters was for Echoes $/ R T$. The relationship found for Reverberance/RT confirmed that $R T$ can be a reasonable predictor of the subjective feeling of reverberance. Reverberance always needed $R T$ or $E D T$ to be predicted by the objective acoustical parameters however, EDT appeared as more suitable to explain the sense of reverberance. 
The relationship Clarity/C80 $\left(\mathrm{R}^{2}=0.72\right)$ also confirms the suitability of $C 80$ to objectively represent the sense of clarity. Nevertheless the EDT (and the $R T$ ) are even better in performing that role $\left(\mathrm{R}^{2}=0.83\right)$. The relationship Overall Impression/EDT $\left(\mathrm{R}^{2}\right.$ $=0.74$ ) also confirms a similar idea concerning this pair of parameters. The relationship Loudness $/ L$ with a $\mathrm{R}^{2}=0.60$ does not fulfill the reasonable expectations regarding their relationship.

\section{ACKNOWLEDGEMENTS}

Sincere thanks go to all those who participated as listeners in this study. We must thank Prof Gary W. Siebein (UF) and Prof Jose Prata (ESMAE-IPP) for valuable comments and interest in this study. We are also indebted to priests and church management for allowing objective and subjective measurements to be made in their churches. The authors wish to recognize the $\mathrm{U}$ of Porto, the Polytechnic Institute of Porto, the JNICT (Portuguese Ministry of Planning), the Direcção-Geral dos Ediffcios e Monumentos Nacionais (Portuguese Board for the National Monuments), the Calouste Gulbenkian Foundation, the U of Florida, the Institute of Construction and the FLAD (Fundação Luso-Americana para o Desenvolvimento) for their financial or technical support in this project.

\section{REFERENCES}

1. António P.O. Carvalho, "Influence of Architectural Features and Styles on Various Acoustical Measures in Churches", PhD Diss. U of Florida, Gainesville (USA), 1994.

2. António P.O. Carvalho, António Morgado and Luis Henrique, "Analysis of Subjective Acoustic Measures and Speech Intelligibility in Portuguese churches". Paper presented at the 131st Meeting of Acoust Soc Am. Indianapolis (USA), May 1996.

3. Richard P. Cervone, Wei-hwa Chiang, Gary W. Siebein, Harold W. Doddington and Wilhelm K. Schwab, "Subjective and Objective Evaluations of Rooms for Music". Paper presented at the 121st Meeting of Acoust Soc Am, Baltimore, MD (USA), May 1991.

4. Wei-hwa Chiang, "A Comparison among Measurements made in Acoustical Models. Measurements made in Full-size Rooms and Subjective Perceptions of Acoustical Quality of Buildings for Music". MS Thesis, U of Florida, Gainesville (USA), 1991.

5. Wei-hwa Chiang, "Effect of Various Architectural PaMmeters on Six Room Acoustical Measur.es in Auditoria". PhD Diss, U of Florida, Gainesville (USA), 1994.

6. António E. Morgado. "Estudo Acustico de Igrejas Portuguesas atraves de Parâmetros Subjectivos" (in Portuguese). MSc Thesis, U of Porto (Portugal), Sept 1996. 